\title{
VOGAIS NASAIS DO FRANCÊS: observações sobre falantes nativos e aprendizes de FLE
}

\author{
FRENCH NASAL VOWELS: \\ observations about native speaker and learners' FLE
}

\author{
Izabel Christine Seara \\ Universidade Federal de Santa Catarina \\ André R. Berri \\ Universidade Federal de Santa Catarina
}

\begin{abstract}
Resumo
Neste estudo, é apresentada uma análise acústica da produção de vogais nasais francesas por falantes nativos e por aprendizes de francês como língua estrangeira (FLE). Tal pesquisa constitui-se de uma análise qualitativa, haja vista o número restrito de vogais examinadas, mas já é possível mostrar que os dados exibidos pelos aprendizes de FLE são mais próximos das vogais nasais do $\mathrm{PB}$, apresentando também variantes que não estão presentes nem no sistema sonoro do francês nem do PB. As produções dos nãonativos representam um espaço acústico menos compacto se comparado ao espaço acústico das vogais nasais do francês.
\end{abstract}

Palavras-chave: Vogais nasais francesas. Análise acústica. Aprendizes de Francês como Língua Estrangeira (FLE).

\begin{abstract}
This study presents an acoustic analysis of the French nasal vowels produced by native speaker and by students of French as foreign language (FLE). This research is a qualitative analysis considering the restricted number of vowels analyzed. Although it is possible to set forth that the exhibited data from FLE students are more similar to the PB nasal vowels, presenting variants which also are not present neither in French sound system and neither in PB. The productions from the non native speakers represent an acoustic space which are less compact in comparison to the French nasal vowels.
\end{abstract}

Keywords: French nasal vowels. Acoustic analysis. Students of French as foreign language (FLE).

\section{INTRODUÇÃO}

Em nossa experiência no ensino de francês como língua estrangeira (FLE), percebemos a dificuldade de pronúncia, digamos, adequada, de alguns sons da língua francesa por falantes nativos do português brasileiro (PB). Mesmo considerando que as abordagens mais atuais de ensino de línguas têm como foco a fluência e não a "correção" da pronúncia, vê-se que, para aqueles que se tornarão professores de Francês, é importante ter uma pronúncia mais adequada do ponto de vista fonético ou pelo menos perceber se 
a sua pronúncia não destoa consideravelmente do que seria esperado para a língua estrangeira que ensina. Como, muitas vezes, o uso da língua por parte desse professor é o único input para seus alunos, essa será a pronúncia que os alunos terão como exemplo. Isso ocorre nas escolas da rede pública que têm Francês em sua grade curricular, uma vez que normalmente os alunos não têm acesso a textos sonoros autênticos, como seria o esperado, ouvindo apenas a leitura dos textos pelos professores.

Além disso, autores, como Baptista (2000), salientam que, nos últimos anos, tem havido grande interesse na utilização de técnicas instrumentais com foco nas distinções fonéticas, haja vista o continuum de diferenças acústicas que ocorrem efetivamente e que são mais bem observadas em análises acústicas. Algumas dessas informações podem ser impossíveis de se perceber de oitiva, até mesmo por um linguista treinado, em função do nível de detalhe fonético fino que apresentam.

Com base nessa situação, elaborou-se uma análise acústica de dados produzidos por falantes nativos do francês e por aprendizes de FLE, tomando, para fins de comparação entre os sistemas sonoros envolvidos, os dados acústicos do português brasileiro (PB) apresentados em Seara (2000) e os do francês exibidos em Delvaux et al. (2002). Nosso objetivo com este estudo será a avaliação, através de técnicas instrumentais, da produção de vogais nasais francesas, tanto de franceses nativos quanto de aprendizes de FLE. Uma das grandes diferenças entre os dois sistemas sonoros, o do PB e o do francês, no que concerne às nasais é que o francês apresenta quatro vogais nasais, sendo

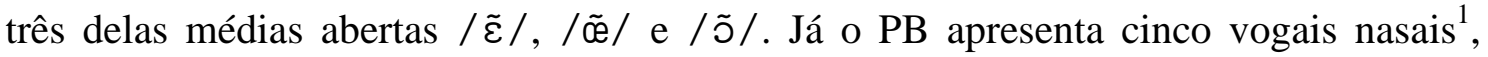
sendo que as médias são fechadas /ẽ / e /õ/ e as altas / ĩ//ũ/ não ocorrem em francês. Veja a seguir, na Figura 1, o gráfico do espaço acústico das vogais nasais do francês e do PB (voltaremos a essa figura mais adiante). Observando a Figura 1, vê-se que as vogais francesas são mais centralizadas, trazendo uma grande redução do seu espaço vocálico nasal em relação ao do PB.

\footnotetext{
${ }^{1}$ Aqui, leva-se em conta apenas teoria monofonêmica relativa às vogais nasais do PB, referenciadas por Pontes (1972), Callou e Leite (1990), Back (1973); ou seja, considera-se a existência de vogais nasais no sistema fonológico do PB.
} 


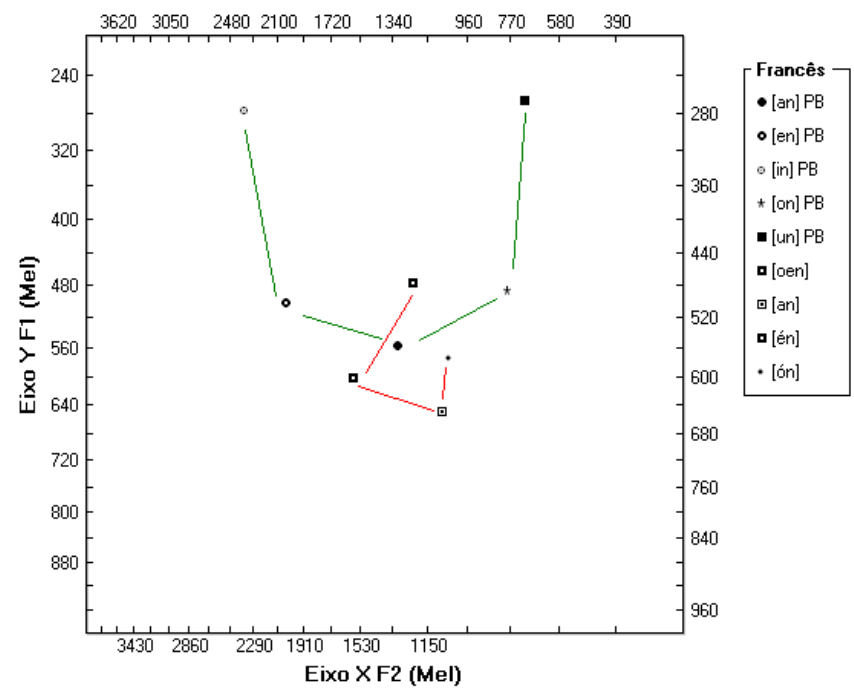

FIGURA 1. Espaço bidimensional definido pelas médias de F1 versus F2 (representados na escala $\mathrm{MEL}^{2}$ ) das vogais nasais do francês (segundo DELVAUX et al., 2002 (linha vermelha)) e do PB (segundo SEARA, 2000 (linha verde)).

Outra questão que deve ser levada em conta é que, diferentemente da aquisição da língua materna que é predominantemente oral, os aprendizes de língua estrangeira, principalmente os que iniciam seu aprendizado já adultos, e não no país da $\mathrm{L} 2^{3}$, são expostos logo de início ao texto escrito. Por essa razão, introduzimos desde já a questão da correspondência grafema/fonema, pois a pronúncia nesse caso terá estreita relação com a grafia. Como essa correspondência de vogais nasais para o PB e o francês é bastante divergente, haverá alguma dificuldade com respeito à pronúncia de certas grafias. No Quadro 1, a seguir, apresentamos essas diferenças.

QUADRO 1. Correspondência grafema-fonema das vogais nasais do francês, conforme WIOLLAND (1983) e HASEN (1998) e do PB

\begin{tabular}{|c|c|c|}
\hline Grafias & Vogais do francês & Vogais do PB \\
\hline UN - UM & $/ \tilde{\varepsilon} / / \tilde{\tilde{e}} /$ & $/ \tilde{\mathrm{u}} /$ \\
\hline ON - OM & $/ \tilde{\mathrm{o}} /$ & $/ \tilde{o} /$ \\
\hline EIN - EIM & $/ \tilde{\varepsilon} /$ & $/$ e $/$ \\
\hline EN - EM & $/ \tilde{\varepsilon} / / \tilde{\mathrm{I}} /$ & $/ \tilde{\mathrm{e}} /$ \\
\hline IN - IM & $/ \tilde{\varepsilon} /$ & $/ \tilde{\mathrm{I}} /$ \\
\hline AIN - AIM & $/ \tilde{\varepsilon} /$ & $/ \mathrm{a} /$ \\
\hline YN - YM & $/ \tilde{\varepsilon} /$ & $/ \tilde{\mathrm{I}} /$ \\
\hline AN - AM & $/ \tilde{\mathrm{a}} /$ & $/ \tilde{\mathrm{e}} /$ \\
\hline
\end{tabular}

${ }^{2}$ Como a percepção humana da frequência não é linear (em Hz), utilizamos, para a representação do espaço acústico das vogais, a escala em unidades mels porque a Escala MEL foi projetada para simular a resposta em frequência do ouvido humano. Essa escala é linear até $1 \mathrm{kHz}$ e logarítmica acima dessa frequência. Por essa razão, achamos mais interessante observar gráficos que representassem as diferenças entre as vogais da maneira como seriam percebidas pelo ouvido humano.

3 Aqui não faremos distinção entre segunda língua (L2) ou língua estrangeira (LE), uma vez que o francês, principalmente no local em que foram coletados os dados do PB, é uma língua estrangeira. 
Como se pode observar, há grafias semelhantes que apresentam pronúncias bastante distintas, como é o caso das grafias UN-UM, IN-IM, EIN-EIM, AIN-AIM, YN-YM. Em outros casos, como para as grafias EN-EM e ON-OM, a diferença se dá apenas na abertura da vogal, como já salientado anteriormente.

Para que se pudesse ter a mesma metodologia de coleta e avaliação dos dados do francês, foram também coletados dados de gravações de falantes nativos do francês para que se observasse a variação na pronúncia de suas vogais nasais em situações menos controladas como em entrevistas e reportagens jornalísticas.

A fim de alcançar o objetivo aqui proposto, a análise de vogais nasais francesas produzidas por falantes nativos do francês e por aprendizes de FLE, este estudo será seguido de mais quatro seções. Na Seção 2, são apresentados alguns estudos com foco em análises acústicas. Na Seção 3, será apresentada a metodologia de coleta e análise dos dados. Na Seção 4, serão mostrados os dados obtidos nas análises e discutidas as diferenças e/ou semelhanças encontradas entre os sistemas sonoros aqui tratados. $\mathrm{Na}$ Seção 5, traremos as conclusões, respondendo às questões levantadas no decorrer desta pesquisa.

\section{REVISÃO DE LITERATURA: ESTUdOS COM FOCO EM ANÁLISES ACÚSTICAS}

Muitos podem ser os objetivos para análise de dados acústicos de diversas línguas do mundo. Um deles, e que nos interessa aqui, é o de descrever os sons em seu continuum acústico com respeito ao seu grau de aproximação a um sistema sonoro em fase de aquisição ou de aprendizagem.

Para este estudo, a noção de "erro" (rejeitada por muitos estudiosos, inclusive DICKERSON (1976) apud BAPTISTA (2000)) é totalmente irrelevante. Flege (1987), dentre outros, tem demonstrado que falantes bilíngues produzem sons de fala que são intermediários aos achados nas duas línguas em contato. Constata ainda que esses aprendizes produzem diferentes variantes, porém incluindo, nessas realizações, as variantes encontradas nas produções de falantes nativos e aquelas que não se encontram nem no sistema sonoro da língua materna (L1) nem no da língua estrangeira (L2 ou LE).

Em Scarduelli e Seara (2006) e Seara (2004), foram analisados acusticamente dados produzidos por aprendizes com diferentes períodos de aquisição e de experiência com a LE. Dois falantes (S1 e S2) aprenderam o francês durante o período de aquisição (antes dos 12 anos de idade) e no país da LE. Um deles (S1) ainda utiliza o francês em suas relações profissionais. O terceiro sujeito (S3) aprendeu o francês já adulto e no Brasil e também utiliza o francês para seus contatos profissionais. Os dados foram obtidos em laboratório através da leitura de frases-veículo e de uma lista de palavras.

Os resultados desses dois estudos, que passaram por testes estatísticos, mostraram que S1 apresentou menos diferenças significativas de suas produções relativas ao padrão francês (obtidos em DELVAUX et al. (2002)), revelando produzir segmentos próximos

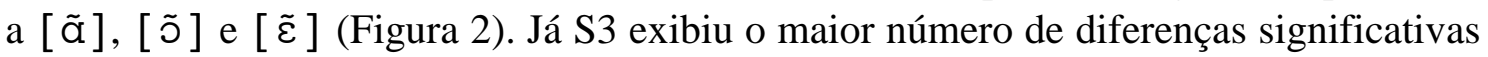


entre suas produções e o padrão francês. Somente nos dados relativos à vogal [ã ] foram obtidos dados mais próximos do padrão (Figura 3). O informante S2 apresentouse em um nível intermediário entre S1 e S3, exibindo dados mais próximos do padrão para as vogais [ $\tilde{\alpha}]$ e $[\tilde{\varepsilon}]$ (Figura 4).

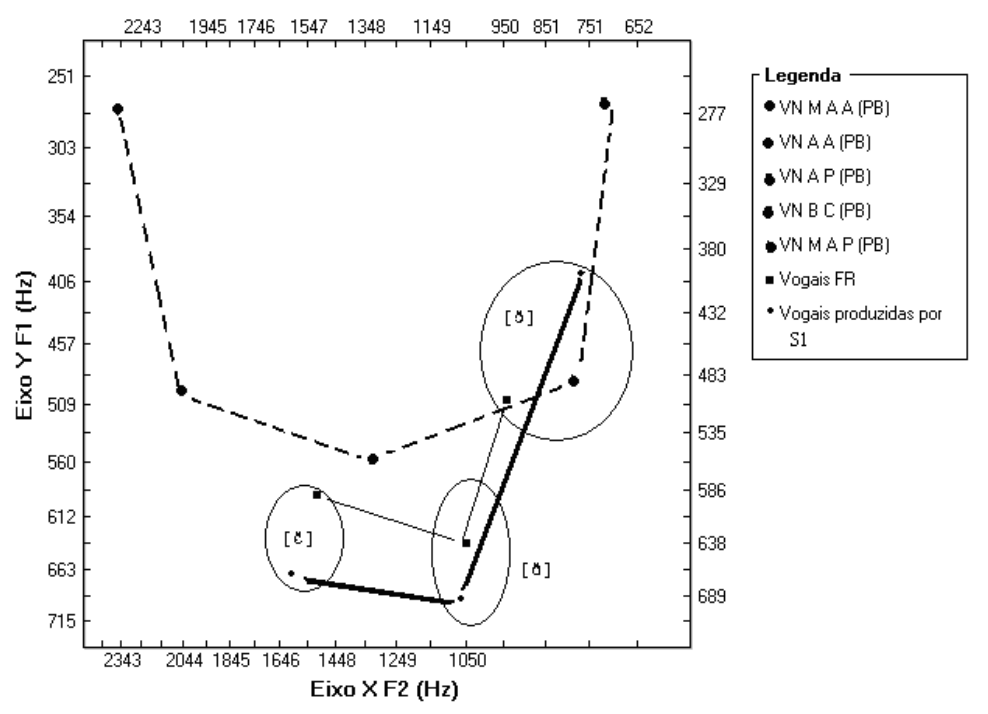

FIGURA 2. Espaço acústico das vogais nasais do francês padrão (linha fina), das vogais nasais do francês produzidas por S1 (linha grossa) e das vogais nasais do português brasileiro (linha pontilhada).

Ainda em Scarduelli e Seara (2006) e Seara (2004), foi observado que as diferenças significativas eram principalmente relativas ao primeiro formante dessas vogais, ficando F2 na faixa apresentada pelas vogais nasais do francês. Esses resultados ratificam os achados de Llisteri (1995) de que os falantes de FLE mantêm o F2 na faixa esperada para as vogais a serem produzidas.

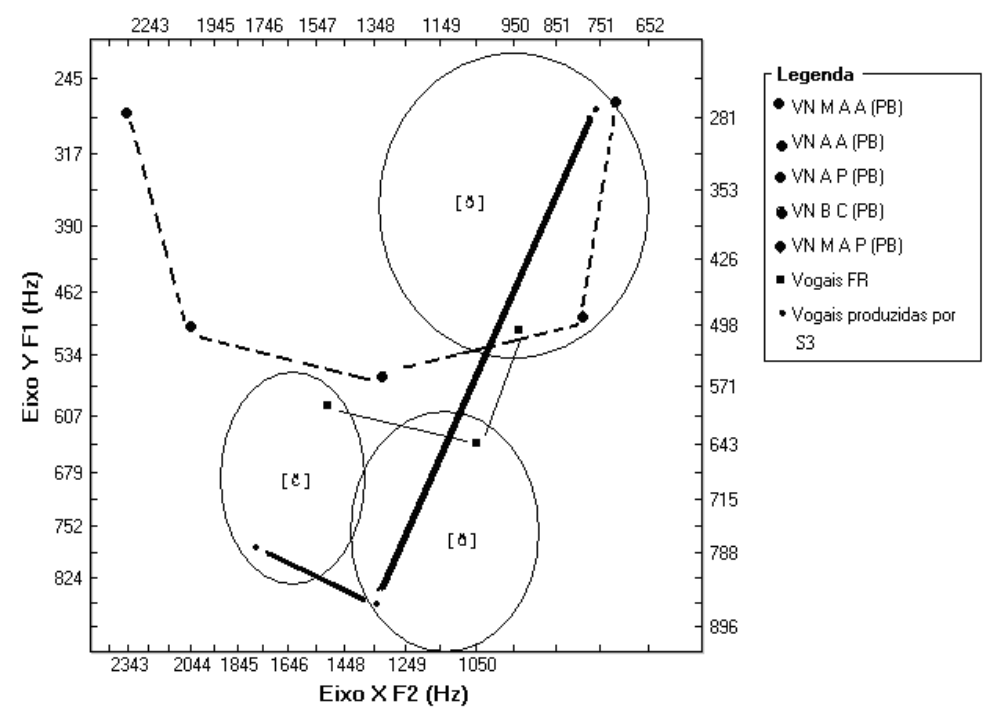

FIGURA 3. Espaço acústico das vogais nasais do francês padrão (linha fina), das vogais nasais do francês produzidas por S3 (linha grossa) e das vogais nasais do português brasileiro (linha pontilhada). 


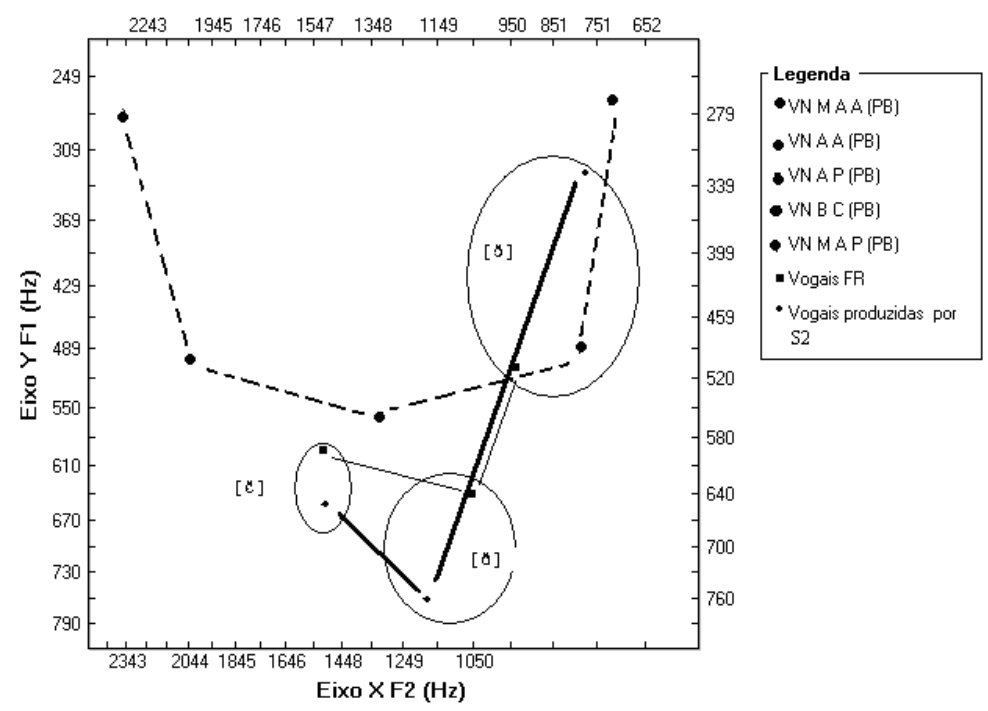

FIGURA 4. Espaço acústico das vogais nasais do francês padrão (linha fina), das vogais nasais do francês produzidas por S2 (linha grossa) e das vogais nasais do português brasileiro (linha pontilhada).

Não queremos aqui fazer uma apresentação exaustiva de estudos concernentes à interlíngua francês/PB, porém gostaríamos de ampliar os estudos já realizados, principalmente, trazendo dados de fala semiespontânea que podem melhor representar a variação encontrada na fala tanto de falantes nativos quanto de aprendizes de FLE. Dessa maneira, com a análise acústica desses dados, vamos tentar responder às seguintes questões:

a) As variantes apresentadas pelos falantes nativos nos dados coletados apresentam uma grande dispersão em relação ao padrão apresentado na literatura da área para o francês?

b) As variantes exibidas nos dados dos aprendizes de FLE são intermediárias entre as duas línguas, contendo também as variantes encontradas em dados de falantes nativos?

\section{METODOLOGIA PARA COLETA E ANÁLISE DOS DADOS}

Foram coletadas gravações de reportagens de dois franceses nativos. As gravações dos falantes nativos foram obtidas pelos sites http://www.cite-sciences.fr e http://www.tv5.org. Essas reportagens foram transcritas e lidas por dois aprendizes de FLE em uma sala sem ruídos. As vogais nasais presentes nesses dados foram todas identificadas e etiquetadas com o auxílio do software Praat ${ }^{4}$. Os dados acústicos (duração, frequência fundamental e frequência dos três primeiros formantes) foram

\footnotetext{
${ }^{4}$ PRAAT - Doing Phonetics by Computer, version 5.1, de Paul Boersma e David Weenink (1992-2009), obtido livremente no endereço eletrônico: www.praat.org
} 
coletados automaticamente a partir das etiquetas. No total, foram analisados 580 dados de aprendizes de FLE e 328 de franceses nativos ${ }^{5}$.

Os aprendizes de FLE eram adultos entre 25 e 30 anos que aprenderam o francês já adultos. Atualmente se encontram em nível intermediário de aprendizagem (correspondendo a dois anos de estudos de língua francesa). Os dados coletados e analisados no presente estudo foram:

a) o primeiro formante (F1), referente à altura da vogal e que é inversamente proporcional ao valor do formante, ou seja, vogais altas têm F1 baixo e vogais baixas, F1 alto.

b) o segundo formante (F2), relativo à anterioridade/posterioridade vocálica. Nesse caso, vogais anteriores (ou que tendem a anteriores) têm F2 alto e vogais posteriores (ou tendendo a posteriores), F2 baixo.

\section{RESULTADOS OBTIDOS ATRAVÉS DAS ANÁLISES ACÚSTICAS}

\subsection{Falantes Nativos do Francês}

Iniciaremos nossa análise pela Figura 5, relativa à grafia [on-om] e à pronúncia de vogal [ õ ] (círculo azul). Nela, percebe-se que poucos dados parecem refletir essa pronúncia. A maior variação diz respeito ao F2 apresentando dados que parecem corresponder às vogais médias um pouco mais anteriores [ ̃̃ ] (círculo rosa) e [ã ] (círculo verde).

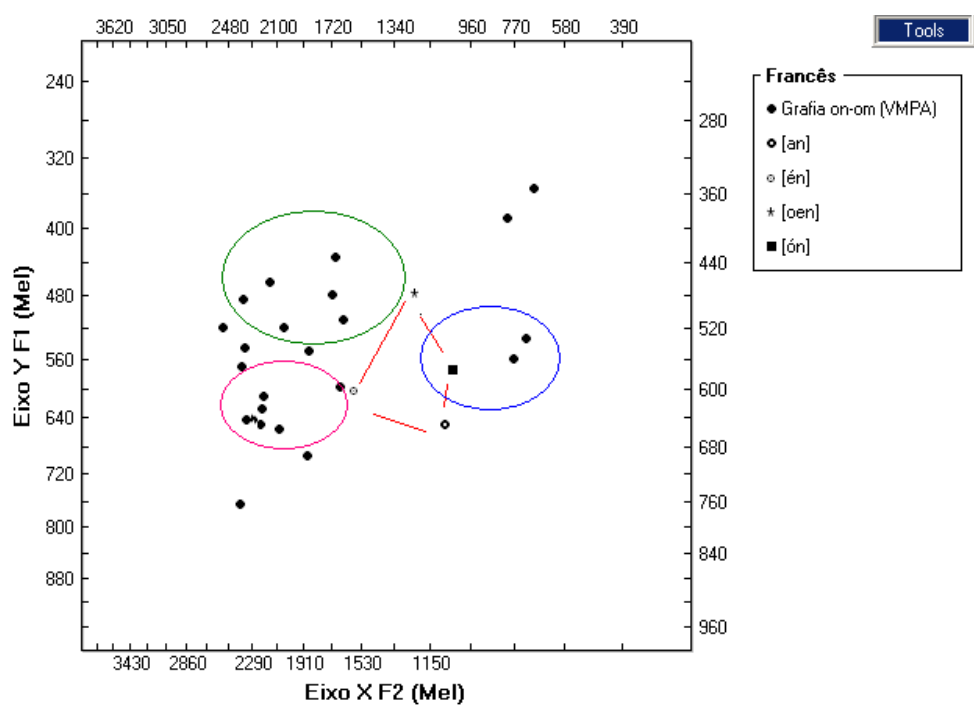

FIGURA 5. Espaço acústico das vogais nasais do francês padrão (linha vermelha) e das vogais nasais relativas à grafia on-om produzidas por falantes nativos do francês (pontos pretos).

\footnotetext{
${ }^{5}$ A diferença entre os dados ocorreram porque em alguns trechos das reportagens de falantes nativos havia som de fundo que encobria a fala natural e esses dados foram descartados.
} 
Agora observando a Figura 6, referente à grafia [an-am] e à pronúncia da vogal [ ã ] (círculo azul), vê-se também que poucos dados parecem reproduzir essa pronúncia. Aqui alguns desses dados (círculo rosa) apresentam pronúncia próxima de [õ], correspondendo essa variação a F1, enquanto outros parecem estar mais próximos da pronúncia de $[\tilde{\varepsilon}$ ] (círculo verde), ficando, nesse caso, a variação de F2 responsável pela produção apresentada.

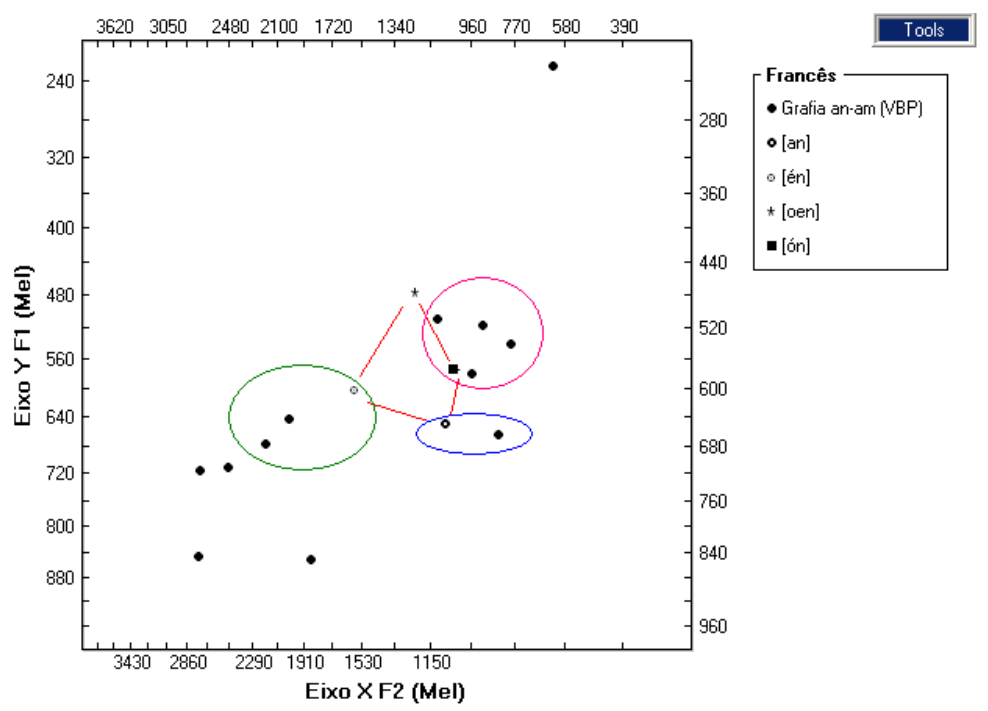

FIGURA 6. Espaço acústico das vogais nasais do francês padrão (linha vermelha) e das vogais nasais relativas à grafia an-am produzidas por falantes nativos do francês (pontos pretos).

Na Figura 7, com respeito às grafias [ein-eim e in-im] e à pronúncia nos dois casos da

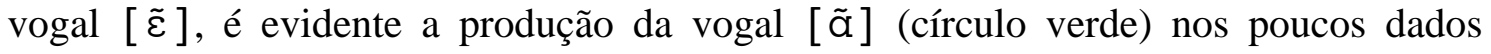
encontrados com essas grafias.

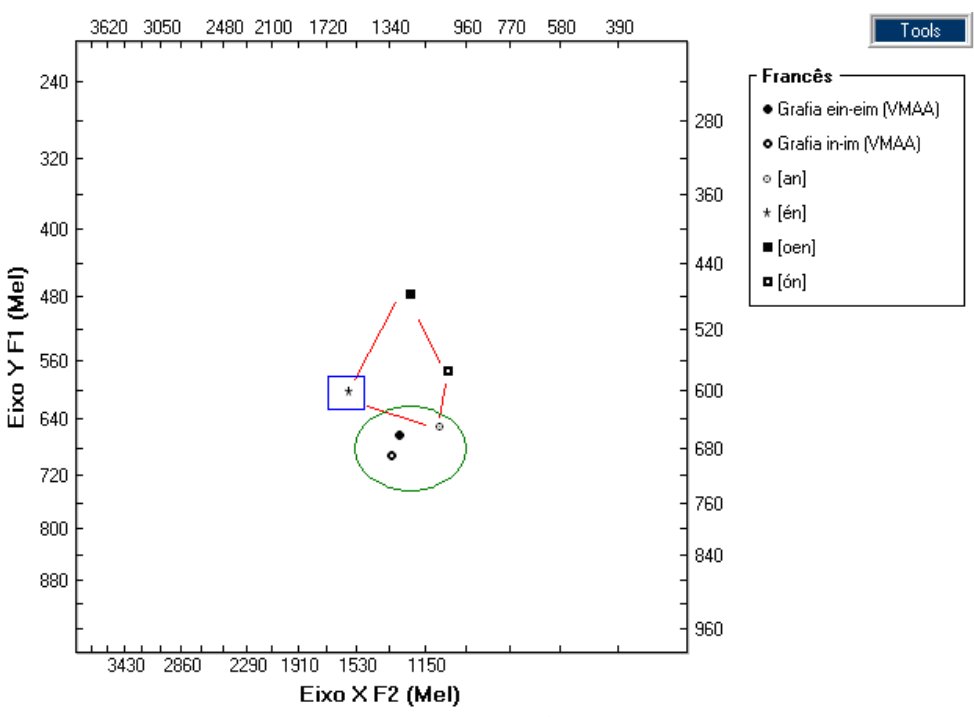

FIGURA 7. Espaço acústico das vogais nasais do francês padrão (linha vermelha) e das vogais nasais relativas às grafias ein-eim e in-im, produzidas por falantes nativos do francês. 
Pela Figura 8, referente às grafias [en-em e un-um] e às pronúncias tanto da vogal [ $\tilde{\varepsilon}$ ]

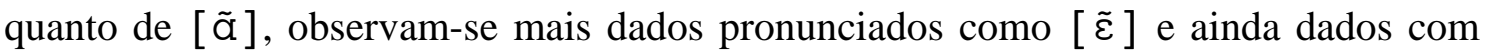
um F1 bem mais alto do que o esperado para essa vogal média do francês (círculo verde). Nota-se, ainda, uma certa quantidade de dados com uma pronúncia mais posterior e mais alta do que a vogal [ ̃̃], a esperada nesses casos (círculos rosas), ou seja, tendendo às vogais médias posterior [ õ ] e anterior [ [ ] .

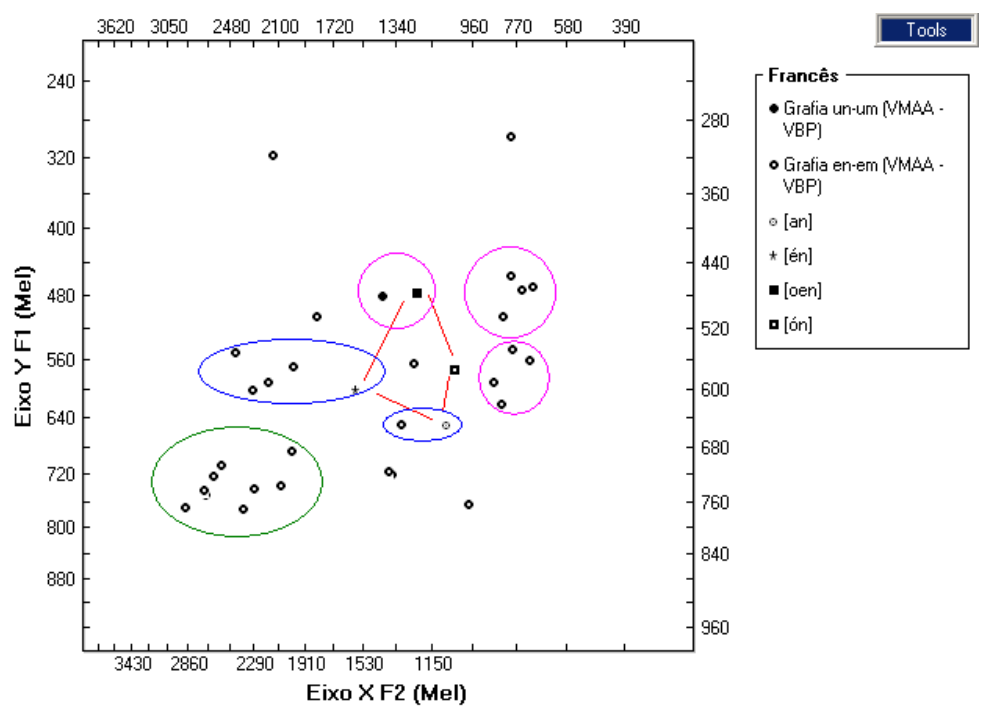

FIGURA 8. Espaço acústico das vogais nasais do francês padrão (linha vermelha) e das vogais nasais relativas às grafias en-em e un-um, produzidas por falantes nativos do francês.

Finalmente, na Figura 9, relativa às grafias [ain-aim e yn-ym] e à produção da vogal [ $\tilde{\varepsilon}$ ], vê-se que há a tendência de produção dessa vogal arredondada, ou seja, da vogal [ã] (círculo verde). Esse arredondamento é verificado pelo abaixamento das frequências de $\mathrm{F}^{6}{ }^{6}$ desses dados.

Analisando os dados de maneira geral, verifica-se que as vogais produzidas pelos falantes nativos do francês apresentam variantes não consideradas na literatura para as grafias correspondentes, mostrando que a fala mais espontânea exibe valores formânticos diversos dos encontrados em ambientes sob controle. Nota-se, no entanto, que os dados mostram F1 mais consistente e F2 mais variável, levando, a partir dos valores do segundo formante, a uma descentralização das vogais nasais produzidas, diferentemente do que apregoa a literatura da área.

\footnotetext{
${ }^{6} \mathrm{O}$ abaixamento das frequências de F3 é um dos correlatos acústicos do arredondamento dos lábios.
} 


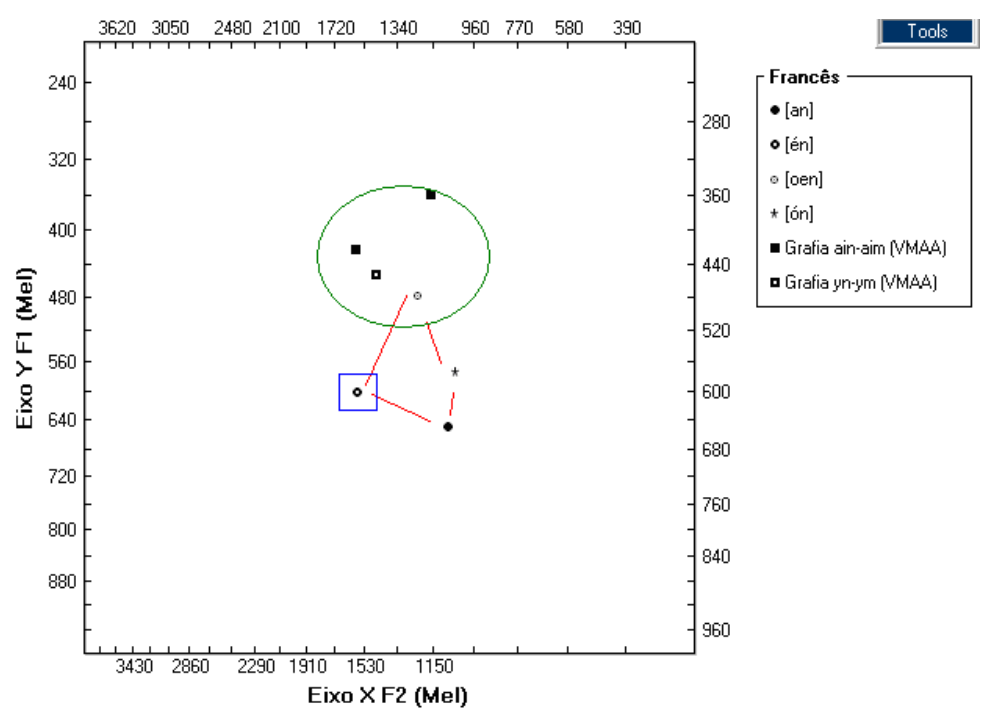

FIGURA 9. Espaço acústico das vogais nasais do francês padrão (linha vermelha) e das vogais nasais relativas às grafias ain-aim e yn-ym, produzidas por falantes nativos do francês.

\subsection{Falantes nativos do PB aprendizes de FLE}

Aqui iniciamos a análise examinando a Figura 10. Nela, vê-se que os dados dos aprendizes, diferentemente dos dados dos nativos se distanciam sobremaneira das médias apresentadas para o padrão francês. Essa figura, relativa às grafias [on-om e anam] e às pronúncias [ õ ] e [ ̃̃], respectivamente, exibe produções mais próximas de uma vogal média anterior (as referentes às grafias on-om) e a uma vogal mais central e alta (as referentes às grafias an-am).

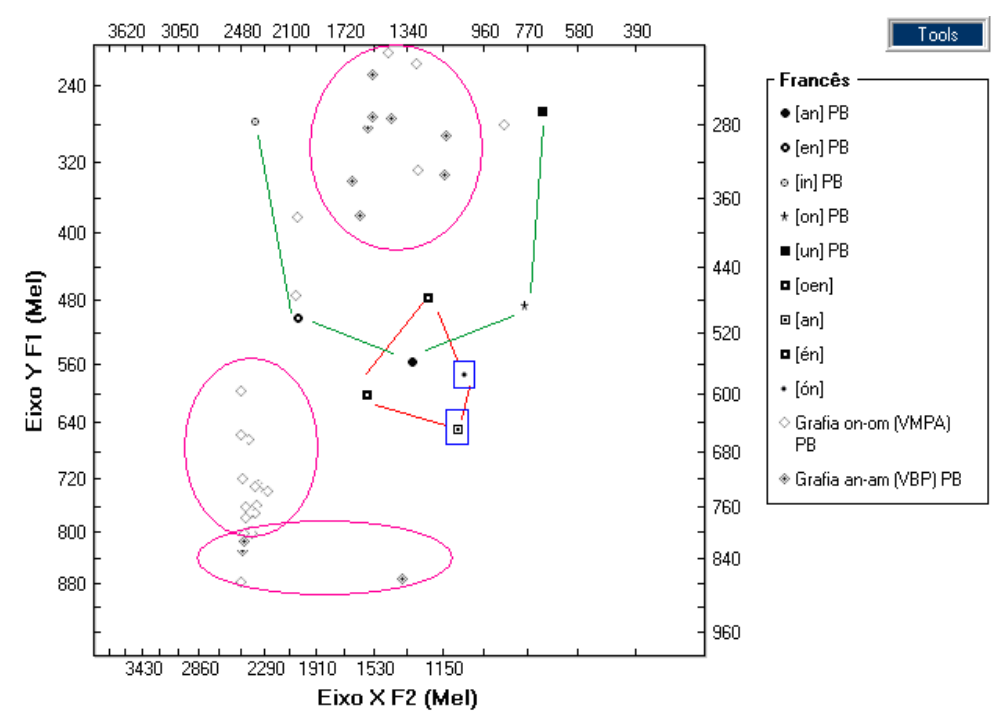

FIGURA 10. Espaço acústico das vogais nasais do francês padrão (linha vermelha), das vogais nasais do PB (linha verde) e das vogais nasais relativas às grafias on-om e anam, produzidas por aprendizes de FLE (círculos rosas).

Observando agora a Figura 11, nota-se que os dados produzidos pelos aprendizes, referentes às grafias [ein-eim e in-im], cuja pronúncia seria a da vogal [ $\tilde{\varepsilon}$ ], apresentam 
valores formânticos divergentes somente em relação à altura vocálica, sendo as produções muito mais altas do que o esperado para o francês

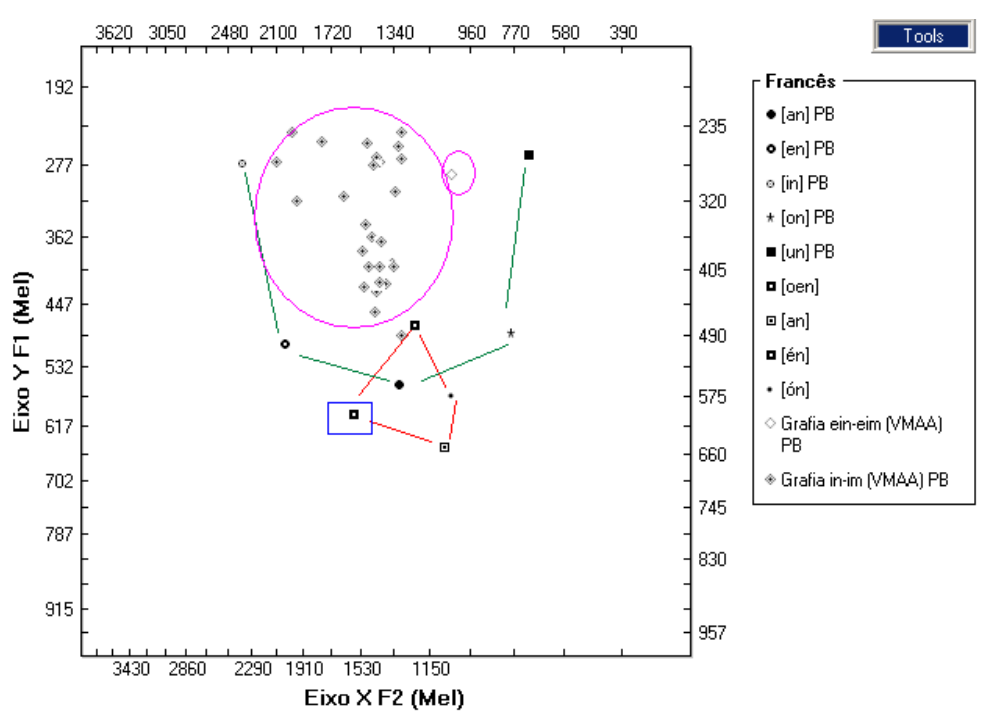

FIGURA 11. Espaço acústico das vogais nasais do francês padrão (linha vermelha), das vogais nasais do PB (linha verde) e das vogais nasais relativas às grafias ein-eim e inim, produzidas por aprendizes de FLE (círculos rosas).

Na Figura 12, que apresenta dados referentes à grafia [un-um] e às pronúncias [ $\tilde{\varepsilon}$ ] ou [थ̃], verifica-se que também os valores são mais altos (F1 mais baixo) do que os esperados para o francês. Novamente a variação ocorre em função de F1.

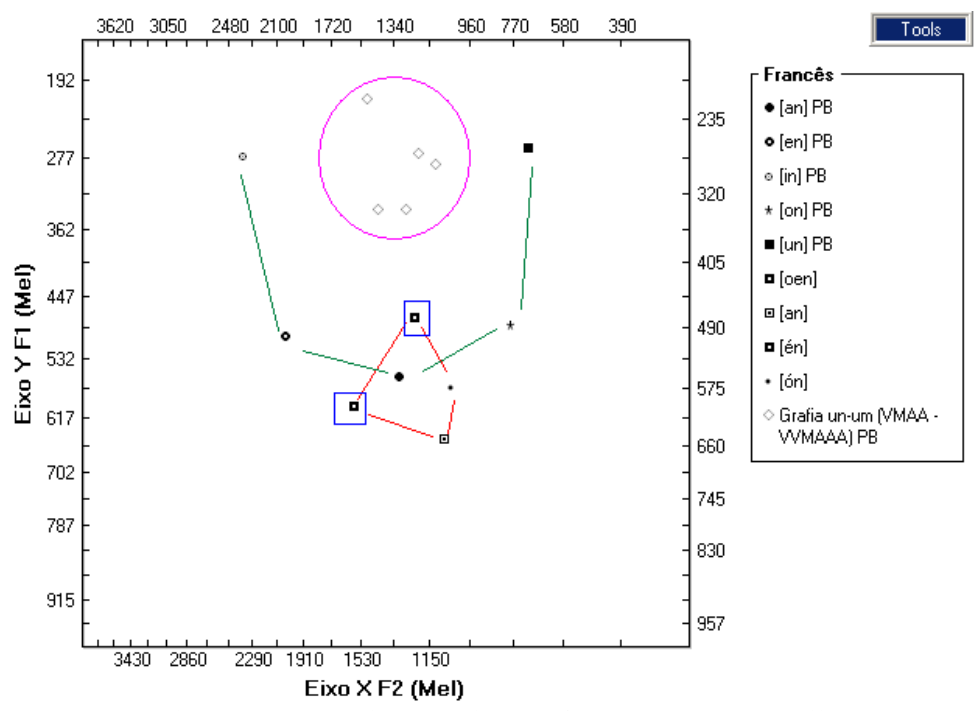

FIGURA 12. Espaço acústico das vogais nasais do francês padrão (linha vermelha), das vogais nasais do PB (linha verde) e das vogais nasais relativas às grafias un-um, produzidas por aprendizes de FLE (círculo rosa).

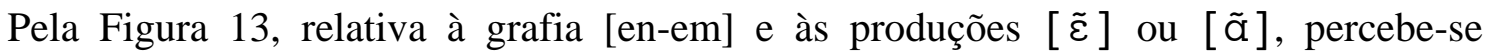
novamente a produção de vogais com um F1 muito mais baixo ou muito mais alto do que o esperado para as produções do francês padrão. 


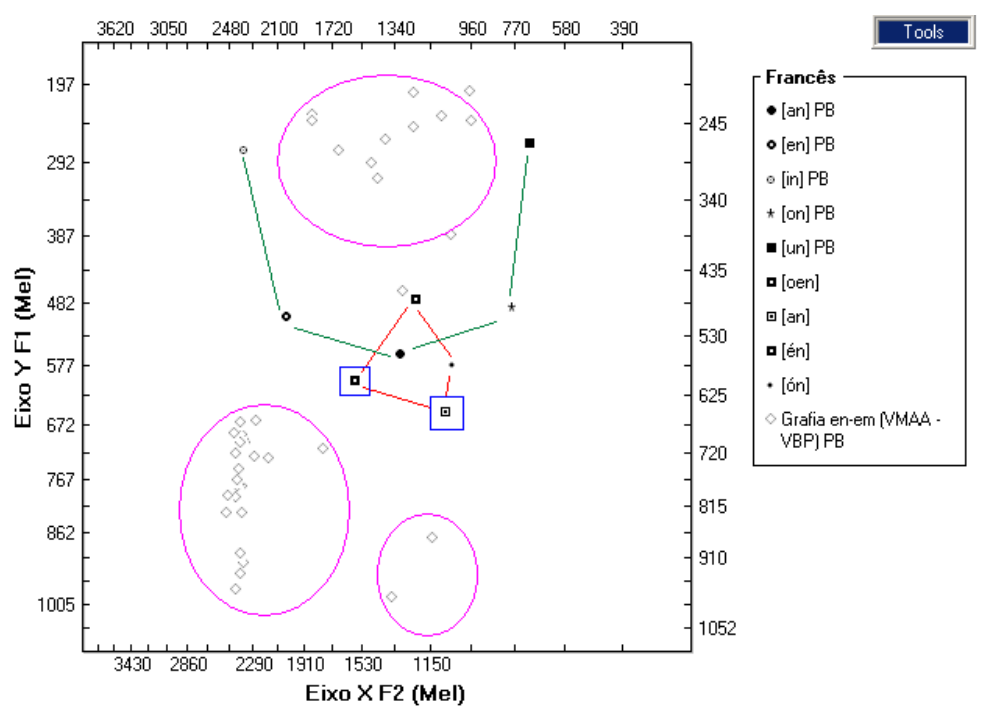

FIGURA 13. Espaço acústico das vogais nasais do francês padrão (linha vermelha), das vogais nasais do PB (linha verde) e das vogais nasais relativas às grafias en-em, produzidas por aprendizes de FLE (círculos rosas).

Finalmente, examinando as Figuras de 10 a 13 em conjunto, verifica-se que os aprendizes de FLE, seja qual for a grafia, produzem principalmente dois tipos de vogais nasais: uma alta central, localizada entre as vogais altas [ [ ] e [ũ ] do PB e uma outra mais baixa do que a vogal [ $\tilde{a}]$ do francês e mais anterior do que $[\tilde{\varepsilon}]$.

\section{CONCLUSÕES}

Aqui respondemos às duas questões colocadas inicialmente que retomamos abaixo:

a) As variantes apresentadas pelos falantes nativos nos dados coletados apresentam uma grande dispersão em relação ao padrão apresentado na literatura da área para o francês?

Os falantes nativos do francês apresentaram dados mais próximos aos esperados, apesar de exibirem um espaço acústico vocálico nasal menos centralizado do que o apresentado pelos dados de Delvaux et al. (2002). Esses dados exibiram variações recorrentemente relacionadas ao F2, sendo F1 mais consistente com os dados do francês padrão. Nesse caso, os falantes nativos apresentaram um comportamento distinto do mostrado em Llisteri (1995) para falantes não nativos.

b) As variantes exibidas nos dados dos aprendizes de FLE são intermediárias entre as duas línguas, contendo também as variantes encontradas em dados de falantes nativos?

Os falantes não-nativos, aprendizes de FLE em nível intermediário, apresentaram, no espaço acústico vocálico de suas produções, as vogais nasais do francês muito mais próximas das vogais do PB, principalmente, em relação à altura da vogal (F1). Ou seja, essas vogais destoaram consideravelmente das vogais nasais francesas principalmente em relação ao parâmetro referente à altura vocálica. Já, as variações relativas ao parâmetro anterioridade-posterioridade vocálica (F2) foram muito menos evidentes. Isso 
pode ratificar as colocações de Llisteri (1995) de que os falantes não-nativos aprendizes de FLE mantêm as frequências de F2 em uma faixa mais próxima das esperadas para o padrão francês. Ou talvez por haver menor possibilidade de variação no espaço ânteroposterior das vogais do que nos graus de abertura (tanto o português quanto o francês apresentam vogais anteriores, centrais e posteriores. Para a altura, o francês exibe apenas vogais médias-baixas e baixas; enquanto o português tem somente vogais altas, médias-altas e baixas). Vimos ainda que algumas das variantes apresentadas pelos nãonativos não estão presentes nem no sistema sonoro do francês nem do PB, ratificando as colocações de Flege (1987). Observou-se também que as produções dos não-nativos representam um espaço acústico menos reduzido se comparado ao espaço acústico das vogais nasais do francês.

Esses resultados complementam e esclarecem um pouco mais sobre o continuum sonoro referente às variações de nativos e não-nativos que são mais bem observadas em dados acústicos. Muito provavelmente estudos deste tipo podem auxiliar os professores de língua estrangeira no (re)conhecimento da variação que pode ocorrer nos sistemas sonoros envolvidos na aprendizagem de uma língua estrangeira. Inclui também mais um grupo de aprendizes de FLE que apresentaram um comportamento distinto do exibido pelos não-nativos pesquisados em Scarduelli e Seara (2006) e Seara (2004).

\section{REFERÊNCIAS}

BAPTISTA, B. O. The acquisition of English vowels by Brazilian-Portuguese speakers. Florianópolis: Ed. UFSC, 2000.

BACK, E. São fonemas as vogais nasais do português? Construtura, São Paulo, n.4, 1973. p. 297-317.

CALLOU, D. e LEITE, Y. Iniciação à fonética e fonologia. 5. ed. Rio de Janeiro: Jorge Zahar, 1990.

DELVAUX, V.; METENS, T.; SOQUET, A. Propriétés acoustiques et articulatoires des voyelles nasales du français. Anais do XXIVèmes Journées d’Étude sur la Parole, Nancy, 24-27, juin, 2002.

FLEGE, J. E. The production of 'new'and 'similar' phones ina foreign language: Evidence for the effect of equivalence classification. Journal of Phonetics, 15, 1987. p. 47-65.

HANSEN, A. B. Les voyelles nasales du français parisien moderne. Aspects linguistiques, sociolinguistiques et perceptuels des changements en cours. Copenhagen: Museum Tusculanum Press. University of Copenhagen. (Livro resenhado por Piet Mertens), 1998.

LLISTERRI, J. Relationships between speech production and speech perception in a second language. Proccedings of the XIIIth International Congress of Phonetic Sciences. Stockholm, Sweden, 1995. 
PONTES, E. Estrutura do verbo em português coloquial. Petrópolis: Vozes, 1972.

SCARDUELLI, J. e SEARA, I. C. A interlíngua: o caso das vogais nasais francesas. Anais do VII Encontro do CELSUL, Pelotas, 18 a 20 de outubro, 2006.

SEARA, I. C. Abordagem acústica das vogais nasais francesas para o auxílio no ensino da pronúncia. Relatório de pesquisa, 2004.

SEARA, I. C. Estudo acústico-perceptual das vogais nasais do português brasileiro. Tese. Florianópolis_SC: Universidade Federal de Santa Catarina: Departamento de Língua e Literatura Vernáculas. Pós-Graduação em Lingüística, 2000.

WIOLAND, F. La rythmique du français parlé. Strasbourg: institute International d’Études Françaises, v. 7, 1983. 